\title{
Effect of Temperature Variation of Intrathecal Bupivacaine on Shivering in Parturients Undergoing Spinal Anaesthesia
}

\author{
Karen Herniques ${ }^{1}$, Amrusha Mukesh Raipure ${ }^{2}$, Dipakkumar Hiralal Ruparel ${ }^{3}$, Naresh Tirpude ${ }^{4}$ \\ 1,3,4 Department of Anaesthesia, Government Medical College and Hospital, Nagpur, Maharashtra, India. \\ ${ }^{2}$ Department of Anaesthesia, All India Institute of Medical Sciences, Nagpur, Maharashtra, India.
}

\section{ABSTRACT}

\section{BACKGROUND}

Shivering is commonly encountered complication following spinal anaesthesia leading to discomfort and interference with monitoring during caesarean section. There is no definite aetiology for this and hence no definite treatment is available. Hence, we wanted to study effect of temperature variation of spinal inject on post spinal shivering during caesarean section.

\section{METHODS}

This prospective randomized double-blind study was conducted on 80 parturients posted for elective caesarean section allocated to two groups of 40 each receiving 2.0 $\mathrm{mL}$ of $0.5 \%$ hyperbaric bupivacaine with temperature of $22^{\circ} \mathrm{C}$ (group I) or $37^{\circ} \mathrm{C}$ (group II) intrathecally at L3 - L4 interspace. Onset of shivering, its severity and incidence were noted. Data was analysed using various tests and P-value $<0.05$ was considered as significant and P-value $<0.01$ was considered highly significant.

\section{RESULTS}

Demographic characters, surgical parameters as well as onset time of sensory blockade, maximum sensory blockade, time to achieve maximum sensory and motor blockade were comparable in the two groups. Shivering was present in $57.5 \%$ of patients in group I and $32.5 \%$ in group II and this difference was statistically significant. Overall, shivering percentage was $45 \%$ although difference in mean onset time was not significant in the two groups. Grades of shivering were comparable in both groups.

\section{CONCLUSIONS}

Warm solutions used intrathecally can reduce incidence of shivering following spinal anaesthesia in caesarean section although it doesn't influence intensity of shivering.
Corresponding Author: Dr. Dipakkumar Hiralal Ruparel, Assistant Professor, No. 202, Gokul Park Tower 1, Besa Belatrodi Road, Manish Nagar, Nagpur - 440015, Maharashtra, India. E-mail:drdruparel@gmail.com

DOI: $10.14260 /$ jemds/2021/94

How to Cite This Article: Herniques K, Raipure AM, Ruparel DH, et al. Effect of temperature variation of intrathecal bupivacaine on shivering in parturients undergoing spinal anaesthesia. J Evolution Med Dent Sci 2021;10(07):425429, DOI: 10.14260/jemds/2021/94

Submission 04-10-2020,

Peer Review 16-12-2020,

Acceptance 23-12-2020,

Published 15-02-2021.

Copyright (C) 2021 Karen Herniques et al. This is an open access article distributed under Creative Commons Attribution License [Attribution 4.0 International (CC BY 4.0)]

\section{KEY WORDS}

Neuraxial Anaesthesia, Temperature Variation, Post Spinal Shivering 


\section{BACKGROUND}

Neuraxial anaesthesia, especially spinal anaesthesia (SA) is a commonly employed technique for caesarean section (CS) and postoperative shivering is a common complication associated with it with incidence of up to $55 \%$, as per review of previous studies. ${ }^{1}$ Shivering can be defined as fasciculation from head, jaw, face or involuntary muscle hyperactivity $\geq 15 \mathrm{~s}$. Hypothermia usually induces shivering but sometimes it is seen in normothermic patient perioperatively. Shivering is often involuntary response of body to cold in order to preserve heat from peripheral vasoconstriction. Various important mechanisms that have been held responsible for intraoperative shivering are loss of heat intraoperatively, increase in sympathetic tone, pain, pyrogens release systemically, and also direct exposure of temperature sensitive neurons located in spinal cord to local anaesthetic solution. Central nervous system as well as spinal cord receiving thermal inputs from various body parts is responsible for body temperature regulation and maintenance.

Although shivering is common, it is often undertreated and leads to maternal discomfort and anxiety apart from its deleterious physiological effects including increased oxygen consumption, increased carbon dioxide production and increased cardiac work which can be troublesome in parturients especially with low cardio respiratory reserve. ${ }^{2}$ It interferes with monitoring of patient and may lead to complications like pain, surgical site bleeding and wound infection.3,4 Many pharmacological and non-pharmacological therapies have been tried in order to prevent shivering perioperatively with varying degree of success. Pharmacological measures include drugs like $\alpha 2$ agonists including clonidine dexmedetomidine, opioids like pethidine, tramadol, central nervous system stimulant, anticholinergic and steroids. Although possible aetiology of shivering is unclear, previous studies suggest that possibly human spinal canal has thermo sensory mechanism which reduces shivering after injection of warm spinal or epidural anaesthetic solution.5,6,7 Study done by Mehta et al. by combine use of warm intravenous fluids and warming local anaesthetic solution before intrathecal injection found reduction in intraoperative shivering. ${ }^{8}$ However, effect of temperature variation of spinal anaesthetic solution on shivering remains controversial.9,10 Hence, we planned to conduct the study with hypothesis that intra-operative shivering is less with injection bupivacaine (heavy $0.5 \%$ ) at $37^{\circ} \mathrm{C}$ as compared to injection bupivacaine (heavy $0.5 \%$ ) at $22^{\circ} \mathrm{C}$ when used for SA in patients posted for elective CS.

\section{METHODS}

After obtaining institutional ethics committee approval and written informed consent from patients, this prospective randomised double blind study was conducted on 80 parturients posted for elective CS at a tertiary care centre from January 2017 to January 2018. Sample size was calculated on the basis of observed shivering proportion during CS in our hospital.

Sample Size $(n)=\{(Z \propto 2 \sqrt{2 p q})+(Z \beta) \sqrt{p 1 q 1}+p 2 q 2\} 2 d 2$

Where, $\mathrm{Z} \alpha / 2=$ is the $\mathrm{Z}$ value at an $\alpha$ error $=1.96$ at $5 \%$ level of significance

$\mathrm{Z}^{\beta}=$ is the $\mathrm{Z}$ value at an ${ }^{\beta}$ error $=80 \%$ power of study $=0.84$

$\mathrm{P}=$ average percentage of the character $=(\mathrm{p} 1+\mathrm{p} 2) / 2$

$\mathrm{P} 1=51 \%, \mathrm{P} 2=22 \%$ are the $\%$ of the character in each group $\mathrm{d}=$ clinically relevant effect size

$$
\begin{aligned}
\text { Sample Size }(n)= & \{(1.96 * \sqrt{2} * 0.365 * 0.635) \\
& +(0.84) \sqrt{0.51} * 0.49+0.22 * 0.78\} 2(0.51 \\
& -0.22) 2
\end{aligned}
$$

Sample Size $=40.42 \approx 40$ in each Group

All participants with singleton pregnancy of American Society of Anaesthesia (ASA) grade I and II, who were age group of 18 to 40 years posted for elective CS were included in study. Parturient who refuse to participate in study, age $>40$ years, ASA grade III \& IV, presenting with acute foetal distress for CS, having fever, pregnancy induced hypertension (PIH), obesity with body mass index (BMI) $>35 \mathrm{Kg} / \mathrm{m} 2$ and requiring blood transfusion / received blood transfusion within 24 hours before CS, failure of spinal anaesthesia (SA) requiring conversion to general aesthesia were excluded from the study. Computer generated randomisation was used to allocate patients in two groups as group-I receiving injection bupivacaine $2 \mathrm{~mL}$ (heavy $0.5 \%$ ) stored at $22^{\circ} \mathrm{C}$ temperature and group-II receiving injection bupivacaine $2 \mathrm{~mL}$ (heavy 0.5 $\%$ ) stored at $37^{\circ} \mathrm{C}$ temperature for SA posted for CS. Separate anaesthesiologist were allocated for preparation and injection of drug while another anaesthesiologist was involved in observation of parameters and data collection. Operating room (OR) temperature was maintained at $23^{\circ} \mathrm{C}$ and all intravenous fluids were warmed at $37^{\circ} \mathrm{C}$. After taking parturient to $\mathrm{OR}$, all standard monitors were attached and preoperative pulse rate, blood pressure, oxygen saturation (Sp02) \& basal temperature of parturient were noted. Intravenous access was established with $20 \mathrm{G}$ intra cath at upper extremity $10 \mathrm{~mL} / \mathrm{kg}$ of Ringer's lactate was infused at least 5 - 10 min prior the subarachnoid block.

With all aseptic precautions, the lumbar puncture was done at L3 - L4 or at L2 - L3 inter-vertebral space in left lateral or right lateral decubitus position with 25G spinal needle and study drug was injected into subarachnoid space. This time was considered as time zero. Patient was made supine and wedge pillow was placed underneath the right buttock. Separate anaesthesiologist was given the task of performing SA and assessment of shivering post spinal anaesthesia. Sensory block was assessed with pin prick test at every one minute for 15 minutes and 5-minute interval for 40 minutes where score 0 was sharp pain, score 1 was touch sensation and 2 was no sensation at all and motor block was assessed using Bromage Scale where score 0 is no block, 1 is ability to flex knees but not the hips, score 2 is unable to flex knees, ankle movement present and score 3 is no movement possible in any of the lower extremities. Time to reach maximum sensory block height (duration in minutes), level of maximum sensory block dermatomal height, and time to achieve Bromage score 3 were noted. A rectal thermometer probe was used to note 
core body temperature at an interval of 5 minutes for initial 30 minutes and for every 10 minutes thereafter till surgery concluded. Crossly and Mahajan scale ${ }^{11}$ was used to grade post spinal shivering where score $0=$ no shivering, score $1=$ no visible muscle activity, but one or more of piloerection, or peripheral cyanosis (other causes to exclude), score $2=$ muscular activity in only one muscle group, score $3=$ moderate muscular activity in more than one muscle group, but not generalized shaking, score $4=$ violent muscular activity that involves entire body. Duration of time between "time 0 " and score 1 was defined as shivering onset time. Parameters such as onset time and the grading of the shivering were noted.

Systolic blood pressure \& heart rate were noted preoperatively, after administration of spinal drug in to subarachnoid space \& patient was made supine, then every 1 2 min till baby was being delivered and later every 5 min till the completion of surgery.

The patients who developed shivering, bradycardia, hypotension were managed \& treated as per hospital protocol (i.e. covering the patient with warming blankets, injection atropine, injection mephentermine etc). The nausea or vomiting or any other intra-operative observations were noted. Hypotension was defined as a fall in systolic blood pressure (SBP) $>20 \%$ or fall in SBP to $<90 \mathrm{~mm} / \mathrm{Hg}$ from the pre-anaesthetic value was treated with injection mephentermine \& crystalloids. If there was profuse blood loss during surgery, the blood transfusion was given to patient but such patients were excluded from the study. Bradycardia was defined as decrease in heart rate $<60$ beats / min and was treated with injection atropine $20 \mathrm{mcg} / \mathrm{kg}$ intravenously.

Apgar score of baby was noted at 1, 5 and 10 minutes interval and was managed by paediatrician as per the need.

\section{Statistical Analysis}

All data was presented as mean \pm SD (Standard Deviation) and Proportion. Demographic data was analysed by Student's t test and chi-square test was used to analyse changes over time. The statistical software Statistical Package for the Social Sciences (SPSS) version 21.0 was used for the analysis of the data and Microsoft Word and Excel have been used to generate graphs and tables.

\section{RESULTS}

80 parturient posted for CS were included in study and divided into two groups of 40 each. Group I received $0.5 \%$ hyperbaric bupivacaine at $22^{\circ} \mathrm{C}$ of temperature and group II received 0.5 $\%$ hyperbaric bupivacaine at $37^{\circ} \mathrm{C}$ of temperature.

Demographic and surgical parameters were comparable in two groups (Table 1). Onset time of sensory blockade, maximum sensory blockade, time to achieve maximum sensory and motor blockade were comparable in both groups (Table 2).

Shivering was present in $57.5 \%$ of patients in group I and $32.5 \%$ in group II and this difference was statistically significant and overall shivering percentage was $45 \%$, although difference in mean onset of time was not significant in two groups (Table 3). The grades of shivering were comparable in both groups. There was no significant difference in incidence of bradycardia, hypotension, nausea and vomiting in two groups.

\begin{tabular}{|cccc|}
\hline Parameters & $\begin{array}{c}\text { Group I } \\
\text { Bupivacaine 22 }\end{array}$ & $\begin{array}{c}\text { Group II } \\
\text { Bupivacaine 370 }\end{array}$ & $\begin{array}{c}\text { P- } \\
\text { Value }\end{array}$ \\
\hline Mean Age (Years ) \pm SD & $27 \pm 3.59$ & $27.05 \pm 2.97$ & 0.61 \\
Mean weight (Kg) \pm SD & $59.75 \pm 6.03$ & $58.52 \pm 3.22$ & 0.25 \\
Mean height (cm ) \pm SD & $156.57 \pm 3.69$ & $156.28 \pm 4.7$ & 0.759 \\
Mean Gestational Weeks \pm & $37.65 \pm 1.44$ & $37.3 \pm 2.17$ & 0.39 \\
SD & $30: 10$ & $27: 13$ & 0.458 \\
ASA Grade I : Grade II & $40.65 \pm 3.81$ & $45.67 \pm 4.71$ & 0.001 \\
$\begin{array}{c}\text { Mean duration of surgery in } \\
\text { minutes }\end{array}$ & \multicolumn{4}{|l}{} \\
\hline \multicolumn{4}{|l|}{ Table 1. Demographic and Surgical Parameters of Patients } \\
\hline $\begin{array}{l}\text { Where SD : Standard Deviation, ASA : American Society of } \\
\text { Anaesthesiologist }\end{array}$
\end{tabular}

\begin{tabular}{|c|c|c|c|}
\hline Parameter & $\begin{array}{c}\text { Group I } \\
\text { Bupivacaine } 22^{\circ} \mathrm{C}\end{array}$ & $\begin{array}{c}\text { Group II } \\
\text { Bupivacaine } 37^{0} \mathrm{C}\end{array}$ & $\begin{array}{c}\mathrm{P}- \\
\text { Value }\end{array}$ \\
\hline $\begin{array}{c}\text { Maximum sensory block } \mathrm{T}_{4} \\
: \mathrm{T}_{6}\end{array}$ & $23: 17$ & $19: 21$ & 0.37 \\
\hline $\begin{array}{l}\text { Onset of sensory block } \\
\text { time in minutes (Mean } \pm \\
\text { SD) }\end{array}$ & $4.08 \pm 0.41$ & $4.05 \pm 0.77$ & 0.85 \\
\hline $\begin{array}{l}\text { Time to achieve maximum } \\
\text { sensory block in minutes } \\
\text { (Mean } \pm \text { SD) }\end{array}$ & $6.33 \pm 0.45$ & $6.24 \pm 0.21$ & 0.26 \\
\hline $\begin{array}{c}\text { Time to achieve motor } \\
\text { blockade (Bromage } 3 \text { ) } \\
\text { (Mean } \pm \text { SD) }\end{array}$ & $7.21 \pm 0.22$ & $7.17 \pm 0.33$ & 0.61 \\
\hline \multicolumn{4}{|c|}{$\begin{array}{c}\text { Table 2. Characteristics of Sensory and Motor Blockade } \\
\text { in Group I and Group II }\end{array}$} \\
\hline
\end{tabular}

\begin{tabular}{|c|c|c|c|c|}
\hline Sl. No & Shivering & $\begin{array}{c}\text { Group I: } \\
\text { Bupivacaine } \\
22^{\circ} \mathrm{C}(\mathrm{N}=40) \\
(\%)\end{array}$ & $\begin{array}{c}\text { Group I I: } \\
\text { Bupivacaine } \\
37^{0} \mathrm{C}(\mathrm{N}=40) \\
(\%)\end{array}$ & P-Value \\
\hline 1 & Present & $23(57.5 \%)$ & $13(32.5 \%)$ & \multirow{2}{*}{0.024} \\
\hline 2 & Absent & $17(42.5 \%)$ & $27(67.5 \%)$ & \\
\hline 3 & Onset time (Min) Mean \pm SD & $14.36 \pm 3.03$ & $12.47 \pm 2.98$ & 0.07 \\
\hline \multicolumn{5}{|c|}{ Table 3. Shivering: In Group I and Group II } \\
\hline Wher & D: Standard Deviation & & & \\
\hline
\end{tabular}

\begin{tabular}{|c|c|c|c|c|}
\hline Sl. No. & $\begin{array}{c}\text { Shivering } \\
\text { Grades }\end{array}$ & $\begin{array}{c}\text { Group I } \\
\text { Bupivacaine } 22^{\circ} \mathrm{C} \\
\mathrm{N}=40(\%)\end{array}$ & $\begin{array}{c}\text { Group II } \\
\text { Bupivacaine } \\
37^{0} \mathrm{C} \mathrm{N}=40 \\
(\%)\end{array}$ & P-Value \\
\hline 1 & Grade I & $9(22.5 \%)$ & $6(15 \%)$ & 0.5679 \\
\hline 2 & Grade II & $8(20 \%)$ & $4(10 \%)$ & 0.3482 \\
\hline 3 & Grade III & $5(12.5 \%)$ & $3(7 \%)$ & 0.7119 \\
\hline 4 & Grade IV & $1(2.5 \%)$ & $0(0 \%)$ & 1.0 \\
\hline \multicolumn{5}{|c|}{ Table 4. Grades of Shivering in Group I and Group II } \\
\hline
\end{tabular}

\section{DISCUSSION}

Shivering is a common side effect of spinal anaesthesia with unclear aetiology with incidence of up to $55 \%$ reported in literature. ${ }^{1}$ Many pharmacological options have been tried for its management with different success rate. Though mechanism of shivering remains largely unknown, few of the factors like loss of vasomotor tone above level of block with resultant loss of vasoconstriction to prevent heat loss, redistribution of heat from core body to periphery, ${ }^{12}$ and increased sweating threshold and decreased vasoconstriction resulting in altered thermoregulations ${ }^{13}$ were few of explanations.

Spinal cord being temperature sensitive as evidenced by its ability to evoke various mechanisms of losing and gaining 
heat including shivering, vasomotion and panting due to change in temperature around it and by distinguishing temperature sensitive anterolateral tract ascending fibres during its thermal stimulation. ${ }^{14}$

In present study, we aimed to compare effect of temperature variation of intrathecal bupivacaine on shivering by adjusting temperature at $22^{\circ} \mathrm{C}$ and $37^{\circ} \mathrm{C}$. We found average incidence of $45 \%$ with group I having higher incidence 57.5 $\%$ ) of shivering than group II (32.5\%) and these findings were similar to study conducted by Najafianaraki et al. ${ }^{7}$ where difference in incidence of shivering in cold and warm bupivacaine group was significant and cold bupivacaine group had higher incidence.

Thermo receptors are present in spinal cord of all mammals, and injecting local anaesthetic solution epidurally that is relatively cool possibly can provoke shivering by triggering local temperature sensors as indicated by previous study. ${ }^{15}$

We found that onset of shivering was faster in group I compared to group II and this was statistically significant. Study conducted by Nandkishor et al. ${ }^{16}$ demonstrated earlier onsets of shivering in cold bupivacaine group i.e. at $4^{\circ} \mathrm{C}$ however there was no statistical difference between group with $22^{\circ} \mathrm{C}$ and $37^{\circ} \mathrm{C}$ finding which does not correlate with our findings.

Intensity of shivering as judged by shivering grades, our study showed $22.5 \%$ of grade I shivering, $20 \%$ of grade II, $12.5 \%$ of grade III and $2.5 \%$ of grade IV in group I (bupivacaine of $22^{\circ} \mathrm{C}$ ), that in group II, $15 \%$ of grade I shivering, $10 \%$ of grade II, $7 \%$ of grade III and 0 of grade IV in group II (bupivacaine of $370 \mathrm{C}$ ), similar results were shown by study conducted by Ponte et al. ${ }^{10}$ where intensity of shivering was comparable in cold group and warm group. We observed similar changes as Ponte et al. ${ }^{10}$ where they observed cooling of extradural space had no effect on intensity of shivering and this difference may be the result of difference in site of injection of study drug. ${ }^{10}$

We did not find any difference in maximum sensory level and maximum motor level and time required to achieve this level and this was similar to previous study by Nandkishor et al. ${ }^{17}$ and Najafianaraki et al.7 Similarly haemodynamics was comparable in both groups.

Although many of previous studies conducted on healthy volunteers and non-pregnant patients demonstrated comparable incidence of shivering irrespective of local anaesthetic solution injected. ${ }^{9,16,17}$ role of temperature of local anaesthetic solution cannot be neglected as evidenced by present study as well as study by Najafianaraki et al.

\section{CONCLUSIONS}

Shivering remains a common concern in patients operated for caesarean section under neuraxial anaesthesia causing discomfort to parturients. Several pharmacological and nonpharmacological measures have been tried to prevent and treat it and there is no gold standard treatment defined for it. The present study demonstrates lesser incidence of shivering with warm local anaesthetic solution injected intrathecally without any difference in incidence of level of blockade and incidence of adverse effects.

\section{Limitations}

It was difficult to maintain particular temperature of bupivacaine and temperature is likely to vary depending on ambient temperature. All efforts were taken to control variables that may affect occurrence of shivering including temperature of room and fluids infused. Also, temperature maintenance system was close to OR and bupivacaine was taken in the CSF was seen on lumbar puncture. Temperature of CSF was not taken into consideration is another limitation.

Data sharing statement provided by the authors is available with the full text of this article at jemds.com.

Financial or other competing interests: None.

Disclosure forms provided by the authors are available with the full text of this article at jemds.com.

\section{REFERENCES}

[1] Crowley LJ, Buggy DJ. Shivering and neuraxial anaesthesia. Reg Anesth Pain Med 2008;33(3):241-52.

[2] Piper SN, Fent MT, Röhm KD, et al. Urapidil does not prevent postanesthetic shivering: a dose-ranging study. Can J Anaesth 2001;48(8):742-7.

[3] De Witte J, Sessler DI. Perioperative shivering: physiology and pharmacology. Anesthesiology 2002;96(2):467-84.

[4] Capogna G, Celleno D. Improving epidural anaesthesia during cesarean section: causes of maternal discomfort or pain during surgery. Int J Obstet Anaesth 1994;3(3):14952.

[5] Gozdemir M, Usta B, Demircioglu RI, et al. Magnesium sulfate infusion prevents shivering during transurethral prostatectomy with spinal anaesthesia: a randomized, double-blinded, controlled study. J Clin Anaesth 2010;22(3):184-9.

[6] Shukla U, Malhotra K, Prabhakar T. A comparative study of the effect of clonidine and tramadol on post-spinal anaesthesia shivering. Isndian J Anaesth 2011;55(3):2426.

[7] Najafianaraki A, Mirzaei K, Akbari Z, et al. The effects of warm and cold intrathecal bupivacaine on shivering during delivery under spinal anaesthesia. Saudi J Anaesth 2012;6(4):336-40.

[8] Mehta P, Theriot E, Mehrotra D, et al. Shivering following epidural anesthesia in obstetrics. Reg Anesth Pain Med 1984;9(2):83-5.

[9] Ponte J, Sessler DI. Extradurals and shivering: effects of cold and warm extradural saline injections in volunteers. Br J Anaesth 1990;64(6):731-3.

[10] Ponte J, Collett BJ, Walmsley A. Anaesthetic temperature and shivering in epidural anaesthesia. Acta Anaesthesiol Scand 1986;30:584-7.

[11] Crossley AW, Mahajan RP. The intensity of postoperative shivering is unrelated to axillary temperature. Anaesthesia 1994;49(3):205-7. 
[12] Lee C, Choi DH, Chae SU. Circadian effects on neural blockade of intrathecal hyperbaric bupivacaine. Korean J Pain 2010;23(3):186-9.

[13] Kurz A, Sessler DI, Schroeder M, et al. Thermoregulatory response thresholds during spinal anesthesia. Anesth Analg 1993;77(4):721-6.

[14] Gerstberger R. Nitric oxide and body temperature control. News Physiol Sci 1999;14:30-6.
[15] Sessler DI. Temperature monitoring and perioperative thermoregulation. Anaesthesiology 2008;109(2):318-38.

[16] Kishore N. The temperature of injectate in spinal anaesthesia affects the onset of shivering. Journal of Clinical and Diagnostic Research 2016;10(1):UC18-21.

[17] Harris MM, Lawson D, Cooper CM, et al. Treatment of shivering after epidural lidocaine. Reg Anaesth 1989;14(1):13-8. 